\title{
Application Analysis of Task - based Teaching in College English Writing Teaching
}

\author{
Li Yan \\ Weinan Normal University, Weinan, Shaanxi, 714000
}

\begin{abstract}
Keywords: College English; Writing teaching; Task-based teaching method
\end{abstract}
\begin{abstract}
For a long time, the teaching mode of college English writing in China is relatively simple. That is to say, the teacher arranges class work, the students finish after class, and the teachers make collective explanations and evaluations, meaning the teaching methods are fixed. The content is empty and the students lack the abilities in English writing, which cannot guarantee its teaching effect. And students in the learning process have poor enthusiasm. As a result, they are difficult for some knowledge with difficult emotions. And improving their writing ability is not obvious. Thus, English listening, speaking, reading, writing and translation are weak. Students, in the process of completing their tasks, learn knowledge and improve their ability.
\end{abstract}

\section{The content and application of the task-based pedagogy}

The task-based pedagogy is a brand-new teaching method, which focuses on the writing ability of students to carry out teaching [1]. With specific learning tasks as a carrier, students are guided to complete the task to master the knowledge and demonstrate the teaching effects through the task outcomes. Teachers in the classroom teaching activities will be designed to learn a series of tasks. Students in the process of completing the task of experience, practice, participation, exchange, natural language learn the second language [2]. In task-based teaching method, the main tasks of the task-oriented teaching method include five aspects: teaching goal, input of task contents, activities of using input materials, roles of teachers and students, learning environment, etc. The teaching goal is to guide students through the completion. A mission is needed to be closed in the real life of students. The use of input materials activities mainly refers to the use of language to learn and use activities. Teachers and students in the role of the teacher is the task of design organizers, monitors, mentors. And students are the task executor and activity participants. Learning environment mainly refers to the organization of classroom teaching and so on [3].

The application of task-based pedagogy in college English writing teaching should follow the following principles [4]: (1) Authenticity. That is to say, the materials involved in the design of tasks during the teaching activities should accord with the actual situation of the students. It is the scene of fulfilling the task. The specific activities and so on should come from life and create a good learning situation for the students. (2) Functional. The biggest problem in traditional English teaching in our country is that it divorced from the real context and weakened the communicative function of language. The task teaching method should follow the principle of function and it clarifies the relationship between language form and function. And it makes learners understand language in accomplishing the task. They enhance learners' understanding of the appropriateness of language. (3) Continuity. The main tasks are the teaching and logically maintain continuity. According to the established steps tasks and teaching content maintain coherence. And the procedures are to complete the task to help student better understand the language acquisition. (4) Operability. In order to avoid too many links, task design must take full account of its maneuverability and simplify the task process. The program is too complicated. It avoids entering the "task for the task of" errors. It not only focuses on the task of the form, but also it considers its effectiveness. The design of classroom tasks is to serve the teaching activities. (5) Fun. One of the biggest advantages of task-based teaching is to stimulate students' interest in learning. It can enhance their learning initiative and guide students to acquire knowledge by completing tasks. Therefore, task design must follow the fun principle to stimulate students' enthusiasm for learning 
and improve learning outcomes.

\section{The specific application of the task-based teaching method}

According to the general procedure of task-based pedagogy, its application in college English writing teaching includes the following aspects [5-6]:

\subsection{Pre-writing tasks}

The so-called pre-writing task is that teachers provide students with specific goals and significance of the task. The specific types include reading summary or feeling, bibliography, experience reports, case studies, comprehensive data, research trials, etc. All aspects of the task are stimulating student interest in writing and improving teaching effectiveness. Teachers can arrange the students to write "resume" writing tasks, personal resume. And student's life is directly related to the actual students to participate in writing tasks. They are also more positive in line with the task-based teaching method of authenticity, functionality, operability. They allow students to try writing "experiment report" to enrich the task content. The arrangement of the previous tasks should pay attention to changing the context and task content of the task so as to help the students in a rich language situation. In order to improve students' English writing skills, we should guide the students to stimulate their different background knowledge and language information in different language forms. After determining the task, the teacher can provide several essays for the students to analyze the key points and highlights of the writing together with the students so that they can better master the writing skills.

\subsection{Medium-term writing tasks}

Mid-term tasks include all aspects of a student's writing process until completion of writing, in which students will write in English according to the teacher's pre-arranged writing task. The students can finish their tasks in the teacher's required time. During the medium-term writing stage, the teacher can distribute students to a number of small groups. Students can study and collaborate on writing contents, writing plans and collecting information. After the first draft of the paper is jointly identified in the group, the teacher writes English. The teacher should make clear the problems to be discussed by each group during the grouping. It includes the content of the writing, the purpose of the writing, the writing attitude to the task, the degree of understanding the content of the writing task, the degree of interest in the writing task, sub-task writing focus, writing task positioning readers and so on. Mutual discussion among the groups can help students to clarify the purpose of writing, exchange writing methods, writing opinions and so on. Upon completion of the group's task, each group nominated a representative to report the results in English and note the fluency and accuracy of the language being written.

\subsection{Post-writing analysis}

After completing the writing task, the students enter into the later stage of analysis. Through the summary and analysis of the tasks, the students form a correct and objective cognition of this writing task. They discuss the problems, improve the problems and improve their English writing skills. After each group completes the group report, the teacher evaluates, analyzes and analyzes the work of each group. The content of the analysis can be the subject of the writing of the article, the argument of a certain viewpoint, the merit of encouraging the students, and the inadequacy pointed out. Pay attention to the writing evaluation of students cannot be too general. It is easy to dampen the enthusiasm of students. To take a variety of evaluation methods, including teacher reviews, student self-assessment, student assessment of each other, the student self-assessment can be summed up the experience of the task to complete. In comparison with this task with the previous task of different, their progress is objective. Student assessment of each other is to evaluate the work of other students and other students in the subtleties of the article and the existence of deficiencies. They put forward constructive comments and suggestions. Student assessment can improve students' ability to identify and modify their self so as to improve students' awareness of 
the application of writing strategies. The teachers' comments will play a finishing touch on the completion of the whole task. Therefore, teachers should make timely and appropriate evaluations of the students' task outcomes. The evaluation process can not focus on the expression of language. The smoothness of sentences and the correctness of grammar can also further the analysis of the structure of the article structured and the integrity of the content. It is not only a simple score or rating. In addition, we should pay attention to the vertical evaluation of students through the progressive evaluation. We give full attention to the progress of students. Evaluation of language should be as detailed and in-depth. Students analyze the pros and cons in terms of writing and broaden their writing ideas.

\section{The application of task-based teaching methods}

Task-based teaching as a teaching method has its advantage. There are naturally its limitations, so the specific application process should pay attention to the following aspects [7-8]:

\subsection{Reasonable control of teaching pace}

Under the traditional English teaching mode in our country, students' learning is mostly passive acceptance, which cannot really reflect its main role in learning activities. At the university stage, students have less chance to speak English. For teachers, task-based pedagogy is also a new teaching mode, which may not be able to guarantee the effectiveness of task design due to lack of experience in designing tasks. Therefore, for teachers accustomed to traditional teaching methods saying is a challenge. It results in a lot of teachers after the design task. The enthusiasm of participating in the task is relatively poor. And it takes a long time to build learning self-confidence. In response to this situation, teachers should step up guidance, start with examples and guide ways to set a reasonable tone for students' participation. They help students get accustomed to their teaching method and create a relaxed teaching environment and set appropriate tasks for completion. The reasonable control of teaching rhythm can ensure the effectiveness of English writing teaching. Teachers should enhance their interaction with students. We prepare teaching materials and provide applicability and operability to students.

\subsection{Change students' learning concepts}

Students accustomed to the traditional teaching methods, task-based teaching in the university stage need to be used to a period of time. Students are accustomed to accept knowledge and to take the initiative to explore knowledge. It is not enough habits. And in the Chinese context English belongs to a second language. It is lack the foreign language acquisition. Immersive language environment, students in the learning process are accustomed to the application of mother tongue. To some extent it will weakened the role of task-based pedagogy. Therefore, teachers should guide students to change their learning concepts and quickly guide them to adapt to the new learning environment and teaching methods. The task-based pedagogy emphasizes cooperative learning. It is a method of doing secondary school. Teachers should help students to learn knowledge and improve their skills through experience in designing science and interesting tasks.

\subsection{Task learning assessment}

The main indicator to evaluate the effectiveness of teaching in the task-based approach is the effect of the task. They do not a separate special test. During the task, teachers should consciously create a relatively real language environment for students, design reasonable learning tasks under the premise of assessing students' learning foundation, and help students to accomplish their tasks better. China's foreign language acquisition environment is different from that of its mother tongue countries. The application of the task-based pedagogy cannot copy its form, but it should grasp the essence of this teaching method. Expanding students' knowledge of foreign languages conforms to the development trend of English writing teaching. It can guide students to "do secondary school" and improve their expressive ability and writing ability. 


\section{Conclusions}

In short, the new curriculum requires students to fully respect the subjectivity of learning activities and the task-based approach to the knowledge point into the specific tasks. Students in the completion of the task master knowledge and improve skills. It can enhance students' writing ability. The task teaching method can fully stimulate students' enthusiasm for learning and improve their ability to analyze and solve problems. This also coincides with the concept of emphasizing the role of students in the new curriculum reform. In the actual teaching process, teachers should fit the students' actual life and interest in the design of the task. In view of the language errors in the process of completing the task, the teacher should be as tolerant as possible to protect students' enthusiasm for learning. In the case of serious grammatical errors, stimulating students' interest in learning and improving the efficiency of writing teaching can improve students' English writing ability.

\section{Acknowledgements}

This work was supported by Educational Reform Project of Weinan Normal University (JG201717).

\section{References}

[1] Li Zhixue, Li Shaoshan. Reflections on the Present Situation of Domestic English Writing - A Statistical Analysis of Ten Kinds of Core Foreign Language Journals in Ten Years (2003-2012) [J].

[2] Li Sen. An important measure to improve the teaching of English writing: process teaching method [J]. Foreign Language World, 2017 (1): 19-23

[3] Feng Yufang, Tang Xiaoyan. Task-based language teaching in the use of English teaching [J]. Foreign Language and Foreign Language Teaching, 2014 (6): 35-38

[4] Ying Whelan University public English teaching reform - a student-centered thematic teaching mode [J]. Foreign language teaching and research, 2016 (4): 308-309

[5] Zhang Xiaoqin. Application of task-driven pedagogy in college English teaching [J]. Journal of Kaifeng Institute of Education, 2014, 34 (11): 137-138

[6] Huang Xiaojie. Task-based teaching in college English writing teaching application [J]. Lanzhou Institute of Education, 2015, 31 (02): 130-131

[7] Wu Ping. Effectiveness of task-driven language block training mode [J]. Foreign Language Education Theory and Practice, 2014 (01): 34-41

[8] Xia Jimei, Kong Xianghui. The theoretical basis and model comparison of "teaching method of problems" and "task teaching method" [J]. Foreign Language World, 2016 (4): 36-391 